\title{
The small-scale spatial distribution of an invading moth
}

Nash, David Richard; Agassiz, David J. L.; Godfray, H. C. J.; Lawton, John H.

Published in:

Oecologia

Publication date:

1995

Document version

Også kaldet Forlagets PDF

Citation for published version (APA):

Nash, D. R., Agassiz, D. J. L., Godfray, H. C. J., \& Lawton, J. H. (1995). The small-scale spatial distribution of an invading moth. Oecologia, 103, 196-202. 


\section{ORIGINAL PAPER}

David R. Nash • David J. L. Agassiz • H. C. J. Godfray

John H. Lawton

\section{The small-scale spatial distribution of an invading moth}

Received: 9 December 1994 / Accepted: 21 February 1995 


\begin{abstract}
We studied the spread of a small leaf-mining moth [Phyllonorycter leucographella (Zeller), Gracillariidae] after its accidental introduction into the British Isles. At large geographical scales, previous work had shown the spread to be well described by a travelling wave of constant velocity. Here, we report the pattern of spread at scales of $1 \mathrm{~km} 2$. By locating all bushes of the insect's foodplant (Pyracanrha spp.) within 1-km2 quadrats, the precise pattern of colonisation at finer spatial scales could be established. Where the $1-\mathrm{km} 2$ site was colonised by moths from the main advancing front, no spatial pattern in the order that bushes were infested was found. If the source of colonisation was a single or small group of infested plants within the site, there was some evidence that nearby plants were colonised first. We found no evidence of population turnover after colonisation. We interpret the results in terms of a two-stage model of invasion that produces different patterns at small and large geographical scales.
\end{abstract}

Key words Invasion · Dispersal Ù Population dynamics • Leaf miner $\cdot$ Spatial scale

\section{Introduction}

The spread of invading animals and plants is a major preoccupation of modern ecology (reviews in Drake et al. 1982; Groves 1986; Kornberg and Williamson 1986; Mooney and Drake 1986; Hengeveld 1989; Andow et al. 1990). An understanding of the ecology of invasions is required in order to predict the consequences of changes to the biota brought about by humans, as well as to manage deliberate introductions of organisms into the environment, for example as part of biological control programmes using natural or genetically manipulated organisms.

David R. Nash . David J. L. Agassiz ' H. C. J. Godfray (E1) John H. Lawton

Department of Biology and NERC Centre for Population Biology, Imperial College at Silwood Park, Ascot, Berks SL5 7PY, UK
The underlying theory of the spread of animals and plants is based chiefly on diffusion processes (Skellam 1951; Okubo 1980, 1988; Britton 1986; Murray 1989). The models predict that the organism should spread through suitable habitats as a travelling wave of constant velocity. In the simplest models, which assume that after colonisation the populations of animal or plant increase in numbers to a constant carrying capacity, the organism reaches a constant density within the colonised range.

An alternative way to view the spread of an organism is in terms of modern metapopulation theory (e.g. Gilpin and Hanski 1991). A metapopulation is a collection of small populations, loosely connected by migration. In so-called "mainland-island" metapopulations, some population (mainlands) are long-lived and send out migrants that colonise smaller sites (islands). Populations on islands tend to be relatively short-lived. In "blinkinglight" metapopulations, all populations are small and relatively short-lived, but the ensemble of populations persists in the environment because of the low probability that all populations will become extinct simultaneously. Invasion processes through metapopulations have received relatively little study from population dynamicists, although more by population geneticists (e.g. Wright 1940). It seems likely that on a geographical, "macroscopic", scale, the range of an invading organism will expand at a constant velocity, as predicted by diffusion models. However, at finer, "microscopic", spatial scales, the wave front is unlikely to appear to progress smoothly, and we expect the occupation of new sites at the margin of the range to occur in a stochastic manner. Moreover, after colonisation, many models of metapopulations predict a turnover of occupancy with extinctions and colonisations occurring at different sites.

Our aim in this paper is to address these questions using the small leaf-mining moth Phyllonorycter leucographella (Zeller) (Gracillariidae). The moth (wingspan 6-8 $\mathrm{mm}$ ) has spread through continental Europe over the last 30 years (see Nash et al. 1994) and was first recorded in the British Isles in 1989 (Emmet 1989) when a survey established that it was confined to an area of 
$11800 \mathrm{~km} 2$ in south-east England (Essex and one locality in north Kent). Since then the moth has spread throughout south-east England and in our latest survey (March 1993) occupied an area of $131400 \mathbf{~ k m 2}$ (Nash et al. 1994). Pyracantha is an evergreen shrub that has been planted widely in gardens as well as in landscaping building developments and amenity areas.

At macroscopic scales, the spread of P. leucographelIa closely approaches the model of constant radial spread. Working at the $100-\mathrm{km} 2$ scale, we found that over a 5-year period (four sample points) the relationship between the square root of range and time was remarkably linear (as expected with constant radial spread), a linear regression explaining $99 \%$ of the variance in the data (Nash et al. 1994). In this study we concentrate on the microscopic scale. We censused the distribution of Pyracantha in ten $1-\mathrm{km}^{2}$ areas in southern England between 1990 and 1992. Six sites were initially chosen in 1990, two in the centre of the range, and four at the edge. The sites were sampled six times over the next 3 years. Four additional sites were added later in the study as new foci of invasions were encountered; these sites were sampled between two and five times. We collected the data to answer the following questions:

1. Does the invading moth spread as a wave through a new site, or is colonisation a piecemeal process with a slow accumulation of infested bushes?

2. After a site is colonised, is there a dynamic turnover of populations? A simple diffusion model predicts an advancing wave with no population turnover; many metapopulation models predict the piecemeal accumulation of infestations across the site, with a turnover of bushes becoming extinct and being colonised.

\section{Methods}

Ten 1-km2 areas were chosen for intensive sampling. Areas with a high degree of urbanisation and hence high density of Pyracantha were selected. Initially, all Pyracantha bushes at the site were identified and mapped. Pyracantha carries brightly coloured berries in the autumn and is easy to locate from some distance. We are confident that all but the smallest bushes at each site were located. The number of bushes per site ranged from 63 to 198. In a few cases, we located bushes but were unable to obtain permission to search them (the majority of bushes were on private land). These bushes are plotted on the maps but enter the analysis as missing values. In a few cases bushes were planted or destroyed during the 3-year course of our study.

During the initial mapping of the sites, we recorded a variety of statistics about each bush: (1) dimensions; (2) variety (leaf shape, stem colour and berry colour); (3) aspect and (4) whether the bush was pruned or not. Each time the bush was visited, the density of P. leucographella was recorded by estimating the percentage of mined leaves. Many bushes were mined at densities below $1 \%$ and these were recorded as a separate category of lowdensity infestation.

The location of the ten sites is shown in Fig. 1. Below we give a brief description of each site. After the name of the site we give the estimated date of colonisation (see Nash et al. 1994), the number of bushes in the $1 \mathrm{~km} 2$, and the sampling dates in months after January 1990. Thus "Chelmsford (1989-72-8, 16, 20, 27, 31, 34)" indicates that a $1-\mathrm{km} 2$ site at Chelmsford was first colonised by the moth in 1989, contained 72 bushes, and was sampled six times in
August 1990, April 1991, August 1991, March 1992, July 1992 and October 1992.

1. Chelmsford (1989-72-8, 16, 20, 27, 31, 34). At the edge of the moth's range when first studied. A suburban site with a relatively low density of bushes. There was an industrial estate in the southwest with few bushes, and a large area of allotments and a cemetery in the middle with no bushes. A new housing estate was built in the south-east during the study where new bushes were planted. 2. Crawley (1991-127-16, 19, 28, 31, 39). In February 1991, 100 heavily infested bushes were planted in the centre of the site at a new supermarket complex. At this time, the main range of the moth was $20 \mathrm{~km}$ to the north. A chiefly residential, suburban site.

3. Gravesend (1988-173-6, 20, 27, 31, 34, 39). At the edge of the moth's range when first studied. The site was on the south bank of the Thames and appeared to have been colonised from migrants that crossed the river. The site was largely residential and contained extensive Pyracantha plantings except in an industrial estate in the north-west.

4. Grays (1987-96-6, 15, 20, 27, 31, 34). Near the centre of the range when first studied. The site consisted of a town centre and residential area but included an industrial estate in the north-west that contained no bushes.

5. Guildford (1991-176-27, 31, 34). A small population was discovered in 1992 in a recently landscaped housing development. At this time, the main range of the moth was $15 \mathrm{~km}$ to the north-east. A chiefly residential site, but containing part of the town centre. 6. Harlow (1990-198-15, 20, 27, 31, 34). At the edge of the moth's range when first studied. A chiefly residential site in a landscaped "new town" with a high density of bushes.

7. Horsham (1992-136-31, 34). An infestation of moths was discovered in a new housing estate in the summer of 1992. Horsham was then $30 \mathrm{~km}$ outside the major range of the moth and the insect was probably brought in on mined bushes. The site was wholly residential.

8. Ongar (1989-131-9, 16, 20, 27, 31, 34). At the edge of the moth's range when first studied. The site consisted of housing estates flanked to the east by agricultural land, the latter containing no Pyracantha. The site was only partially sampled in September 1990 (month 9).

9. Takeley (1991-63-17, 27, 31, 38). Mines were first noted in May 1991 when the distance to the front of the invasion was approximately $5 \mathrm{~km}$. Colonisation of this site was thus probably natural. Takeley is a small village, all contained within the site, and surrounded by agricultural land. To the west of the village is a recently built housing estate, on which much Pyracantha had been planted.

10. Wickford (1986-110-8, 15, 20, 27, 31, 34). At the centre of the moth's range when first studied. A mixture of residential areas with many Pyracantha bushes, and a more built-up town centre with fewer bushes.

To study whether those bushes nearest the advancing front are more likely to be colonised by the moth, we conducted a statistical analysis where the binary response variable is the observation that an uncolonised bush is or is not discovered by the moth over a certain time period. The explanatory variable is the distance from the side of the $1-\mathrm{km} 2$ square nearest the advancing front, or the distance from a diagonal line through the corner of the square nearest the front. We measure distance from the side of the square when the front is largely advancing from the south, north and so on; and from the diagonal through the the corner when the main direction of the front is from the south-east, north-east and so on. We used binary logistic regression as implemented on the GLIM statistical package. The resultant statistic has an asymptotic ${ }^{2}$ distribution. To obtain the maximum statistical power, we performed the analysis at each site over a period during which as near as possible $50 \%$ of the initially uncolonised bushes were located by the moth.

\section{Results and discussion}

The distribution of bushes in the ten sites is shown in Fig. A1 (Appendix). The following overall statistics for 


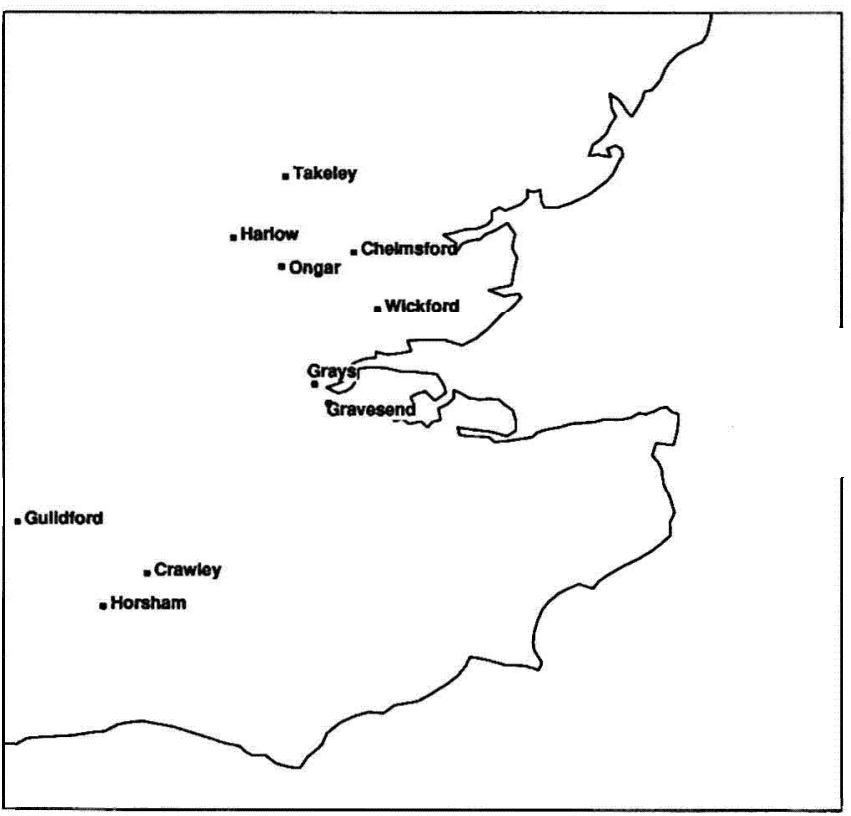

Fig. 1 The locations of the ten sample sites in south-east England

each site are shown in Fig. 2: (1) the proportion of bushes containing leaf mines; (2) the proportion of bushes with more than $1 \%$ of their leaves mined; (3) the number of bushes that have been colonised since the last sample (expressed as a proportion of all bushes) and (4) the number of bushes on which populations have become extinct since the last sample (expressed as a proportion of all bushes). We analyse the results by answering the questions posed in the Introduction.

At the microscopic scale, does the invading moth spread as a wave through a new site, or is colonisation a piecemeal process with a random accumulation of infested bushes?

We can answer this question using data from the four sites that were selected as near the edge of the range at the beginning of the study, and using data from the four sites representing new foci of invasion.

The four sites in the first category are Chelmsford, Gravesend, Harlow and Ongar (see Fig. Al). At Chelmsford, $50 \%$ of bushes were attacked when the site was first sampled, the proportion rising to about $95 \% 2$ years later (Fig. 2). The pattern in this site is of a gradual filling up with no tendency for southerly sites (the direction from which the front advances) to be colonised first (there was no significant relationship between the probability of colonisation of bushes and their distance from the southern boundary of the site: $22.20, \mathrm{df}=1, \mathrm{P}=0.14$ ). At Gravesend, the source of colonisation is to the north. Initially, the moth was confined to two places in the north of the site, a bush and a series of bushes growing close together. However, over the course of the study, the proportion of mined bushes rose to over $90 \%$ (Fig. 2). Sites nearer the northern boundary were not colonised first; indeed, there was a nearly significant tendency for the reverse to occur $(23.74, \mathrm{df}=1, \mathrm{P}=0.053)$. At Harlow, the source of colonisation is to the south-east. Over the course of the study, the proportion bushes mined rose from $25 \%$ to $90 \%$ (Fig. 2) but again with no obvious spatial pattern. Distance from a diagonal line through the south-east corner of the square was not a significant explanatory variable $(20.16, \mathrm{df}=1, \mathrm{P}=0.69)$. The final edge-of-range site was at Ongar, although the first time the site was fully sampled over $70 \%$ of bushes were colonised. The source of colonists here is, as at Harlow, towards the south-east and the same analysis as that performed there showed no directional bias in the probability of colonisation $(20.23, \mathrm{df}=1, \mathrm{P}=0.63)$.

Thus the analysis of the four edge-of-range sites strongly suggest that at this finer scale of resolution the pattern of colonisation of the moth is not a simple wave but a more complex saltational process in which some bushes in a site are colonised, apparently at random, followed by a gradual process of filling in as population densities grow.

We now turn to the four sites which represent sites where we monitored the complete process of invasion. At Crawley the initial infestation was at two nearby locations within the site. Over the course of 2 years, the proportion mined bushes increased from $6 \%$ to $22 \%$. Examination of the distribution of mined bushes (Fig. 3), shows a definite tendency for plants near the source of initial infestation to be colonised first. We were also able to locate the foci of infection at Horsham and Guildford (Fig. A1). The pattern of spread at these sites appears similar to that at Crawley although the sites were not sampled for a long enough period to establish this pattern conclusively. Finally, at Takeley we observed the whole process of invasion although the source of colonists was not a single focus as at Crawley, Horsham and Guildford, but the main advancing front of insects. The proportion of mined bushes increased from $0 \%$ to $64 \%$ over the sampling period but there was no directional pattern of colonisation. This site thus appears similar to the edge-of-range sites studied in the first part of this section.

After a site is colonised, is there a dynamic turnover of populations?

To answer this question we first examine the two centreof-range sites. We then look at extinction and colonisation patterns in those other sites where the moth reached a high density during the course of the study.

At Grays, the proportion of bushes mined increased from $67 \%$ to $99 \%$ over the 30 months of sampling. There was very little extinction except between April and August 1991, when $19 \%$ of largely low-density bushes lost their populations (Fig. 2). The extinctions showed no strong spatial pattern. At Wickford, the proportion of 

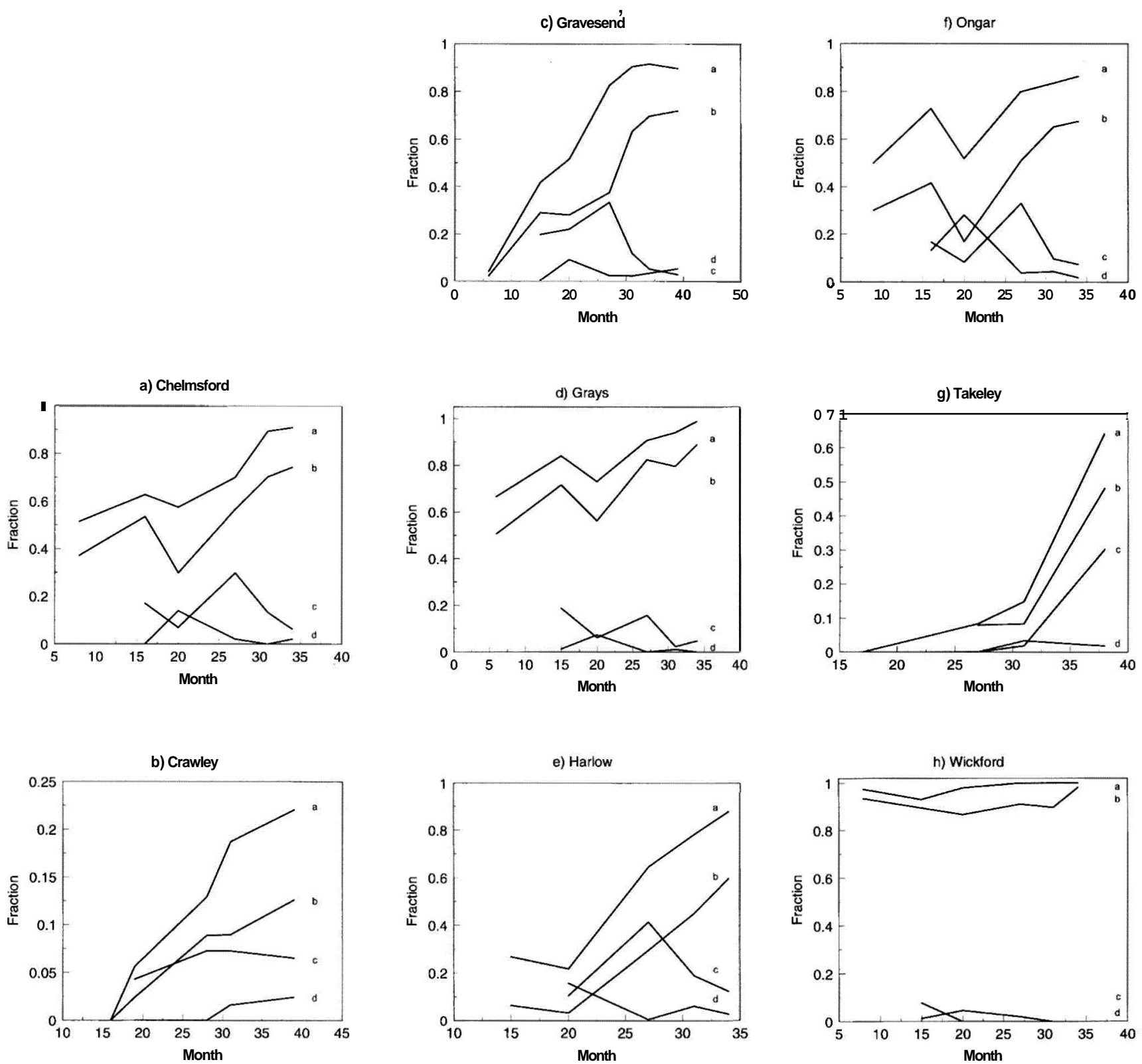

Fig. 2a-h Summary statistics for the sites used in the study of population turnover (a the proportion of bushes containing leaf mines, $b$ the proportion of bushes with more than $1 \%$ of their leaves mined, $\mathrm{c}$ the number of bushes colonised since the last sample expressed as a proportion of all bushes, $\mathrm{d}$ the number of bushes on which populations have become extinct since the last sample expressed as a proportion of all bushes). Data for eight sites are shown (Guildford and Horsham were only sampled three and two times respectively): a Chelmsford, b Crawley, c Gravesend, d Grays, e Harlow, f Ongar, g Takeley, h Wickford

bushes mined did not drop below 93\% and was exactly $100 \%$ for the last three samples.

At Chelmsford, extinctions were rare except between April and August 1991, when 14\% of populations on bushes became extinct. Again these were largely lowdensity populations. Similar patterns were found at Gravesend, Harlow and Ongar (Fig. 2), the three other

populations that had reached appreciable densities by 1991.

Thus there is little evidence of a dynamic turnover of populations within the sites. The only appreciable episodes of extinctions observed were between spring and summer 1991. Because the sampling regime detects mines rather than moths, the extinctions causing this pattern would have occurred over the winter, probably associated with hard weather. The extinctions were largely confined to populations that had previously been at densities below the level of $1 \%$ mined leaves.

\section{Other patterns}

In addition to our primary questions, we also explored whether the probability that a bush is colonised is related to its size, variety, aspect or whether it is pruned. We ex- 

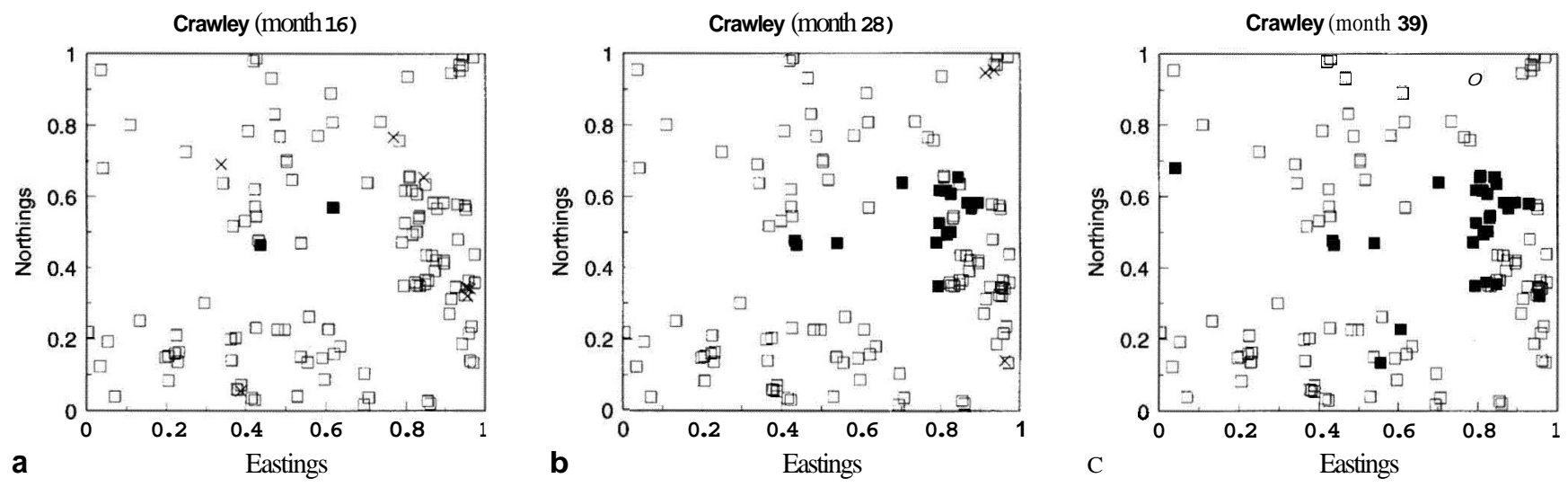

Fig. 3a-c The distribution of infected and uninfected Pyracantha bushes at the Crawley site in a April 1991, month 16; b April 1992, month 28; and c March 1993, month 39 (filled squares infested bushes, open squares uninfested bushes, crosses missing values)

amined these questions at two sites, Takely and Gravesend. At Takely we analysed the probability of colonisation by the end of the study while at Gravesend we analysed the probability of colonisation by July 1992 (the proportion of bushes attacked subsequently approached 1). Analysis was by logistic regression and analysis of deviance using the GLIM statistical package (Collett 1991; Crawley 1993). In neither case did we find any statistically significant associations between colonisation probability and any of the explanatory variables.

\section{Conclusions}

At this "microscopic" scale (bushes within $1 \mathrm{~km} 2$ ) our findings provide no strong evidence for either a simple travelling-wave model of invasion, or for a metapopulation model. If the invasion was a strict travelling wave, we would expect infestations of the moth to occur first in parts of the sites nearest the source of colonists. There was no evidence of this from any site that was colonised by the main front of invading moths. If a strict metapopulation model was appropriate, we would expect to see a dynamic turnover of sub-populations. In fact we observed very little extinctions, except during one winter and then mostly affecting very low density bushes. The observation that at one site (Wickford) nearly $100 \%$ of bushes were continually attacked, and that infestations approached $100 \%$ towards the end of the study at other sites, also argues against a metapopulation. If extinction and colonisation are occurring continually - the classical metapopulation - then at equilibrium a constant (although spatially fluid) proportion of bushes would have been expected to be unoccupied. This was not what we observed. Rather, the final pattern of occupancy across bushes resembles what Harrison (1991) terms a "patchy population" where high rates of dispersal effectively unite the patches into a single demographic entity with essentially no potential for extinction of discrete local populations.

The absence of spatial pattern from "microscopic" surveys at the 1-km2 scale of the main advancing front is in marked contrast to "macroscopic" surveys of the entire south of England at a scale of individual $10 \mathrm{kmxl10km}$ squares (Nash et al. 1994). At this larger scale, the pattern of colonisation (occupied or unoccupied $10 \mathrm{kmx10} \mathrm{km}$ squares) appears to conform very closely to a travelling wave of constant velocity. In other words, whether or not the simple patterns predicted by theoretical models are observed depends critically upon the scale at which the process is studied [see Levin (1992) for a discussion of invasions and spatial scale].

Our data are consistent with the following two-stage model of invasion. When the moth is introduced at a single point in an occupied habitat, it spreads from an initial focus to neighbouring bushes. Such movements produce spatial structure at the scale of under $1 \mathrm{~km}$ that was employed in this study. We have clear evidence of such patterns from Crawley and suggestive evidence from Horsham and Guildford. This pattern of movement is different from the spread of the moth produced by the main front of the invasion. Here, sites at the edge of the range appear to receive a random rain of potential colonists. The randomness is at the scale of $<1 \mathrm{~km}$; at larger geographic scales, the spatial structure is much clearer (see above). Within the $1-\mathrm{km}^{2}$ squares, the proportion of bushes that are attacked by the insect increases with time in a logistic manner until the proportional occupancy approaches or reaches 1 .

Acknowledgements We are very grateful to the Department of the Environment who funded this research and the many people who allowed us access to their Pyracantha bushes. 


\section{Appendix}

The spatial distribution of the Pyracantha bushes in the ten sites is shown in Fig. Al.

Fig. A1 The distribution of Pyracantha bushes at the ten 1-km² sites studied
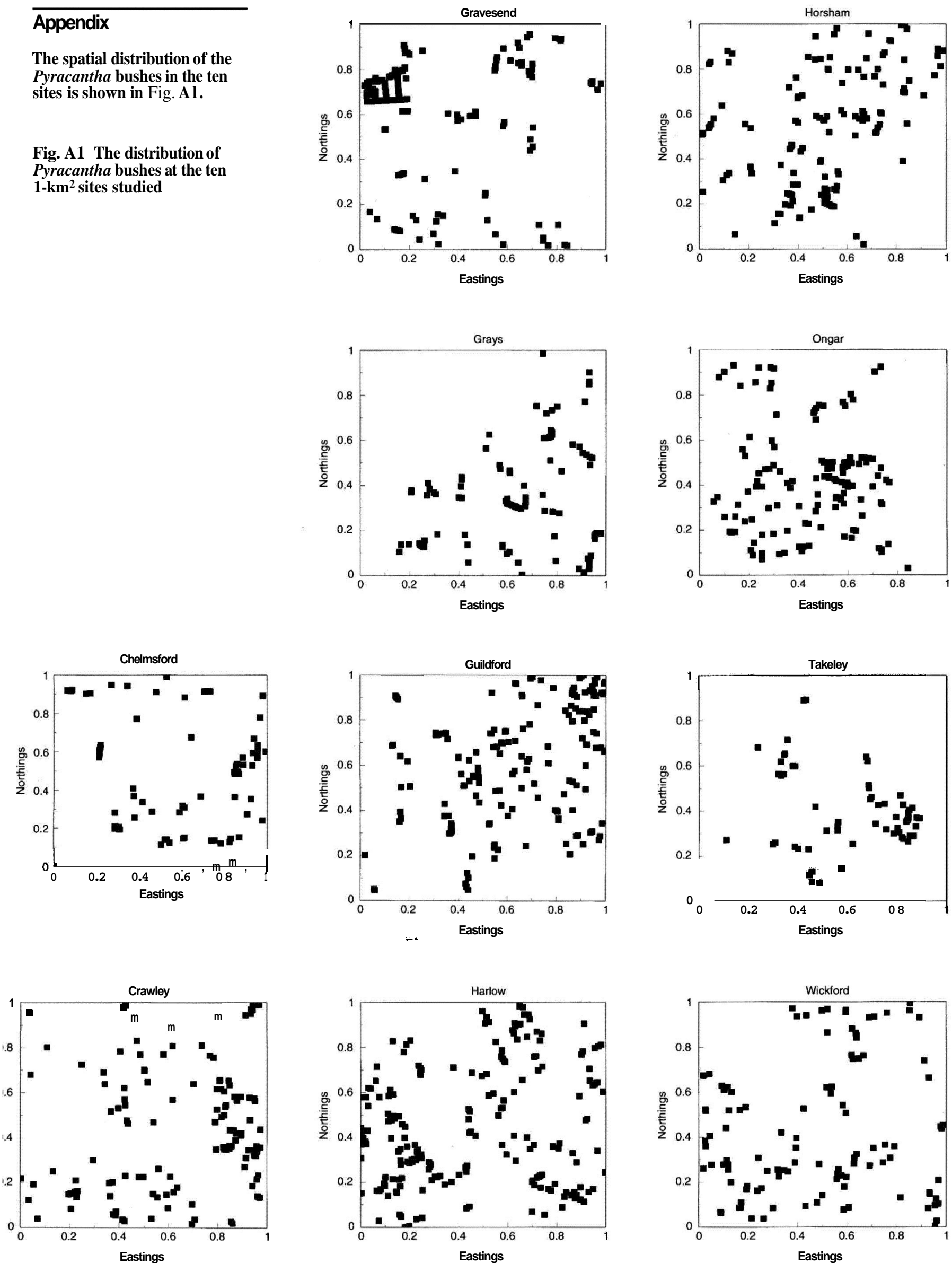


\section{References}

Andow DA, Kareiva PM, Levin SA, Okubo A (1990) Spread of invading organisms. Landscape Ecol 4:177-188

Britton NF (1986) Reaction-diffusion equations and their applications to biology. Academic Press, London

Collett D (1991) The analysis of binary data using GLIM. Chapman and Hall, London

Crawley MJ (1993) GLIM for ecologists. Oxford University Press, Oxford

Drake JA, Mooney HA, Castri F di, Groves RH, Kruger FJ, Rejmanek M, Williamson M (eds) (1989) Biological invasions, a global perspective. Wiley, Chichester

Emmet AM (1989) Phyllonorycter leucographella (Zeller, 1850) (Lep., Gracillariidae) in Essex: a species new to Britain. Entomol Rec J Var 101:189-194

Gilpin M, Hanski I (eds) (1991) Metapopulation dynamics: empirical and theoretical investigations. Academic Press, London

Groves RH (1986) Ecology of biological invasions. Cambridge University Press, Cambridge

Harrison S (1991) Local extinctions in a metapopulation context: an empirical evaluation. Biol J Linn Soc 42:73-88

H e n g e v Rl (11989) Dynamics of biological invasions. Chapman and Hall, London
Komberg H, Williamson MH (1987) Quantitative aspects of the ecology of biological invasions. The Royal Society, London

Levin SA (1992) The problem of pattern and scale in ecology. Ecology 73: 1943-1 967

Mooney HA, Drake JA (1986) Ecol ogy of biological invasions of North America and Hawaii. Springer, Berlin Heidelberg New York

Murray JD (1989) Mathematical biology. Springer, Berlin Heidelberg New York

Nash DR, Agassiz DJL, Godfray HCJ, Lawton JH (1994) The pattern of spread of invading species: two leaf-mining moths colonising Great Britain. J Anim Ecol 64:225-233

Okubo A (1980) Diffusion and ecological problems: mathematical models. Springer, Berlin Heidelberg New York

Okubo A (1988) Diffusion-type models for avian range expansion. In: Quellet W (ed) Acta XIX Congress Internationalis Ornithologici (vol 1). University of Ottawa Press, Ottawa, pp $1038-1049$

Skellam JG (1951) Random dispersal in theoretical populations. Biometrika 38:196-218

Wright S (1940) Breeding structure of populations in relation to speciation. Am Nat 74:232-248 